Bull. Mater. Sci., Vol. 4, Number 1, March 1982, pp. 43-46. (C) Printed in India.

\title{
A simple technique for interference microtopography
}

\author{
P B V PRASAD and I V K BHAGAVAN RAJU* \\ Department of Physics, Government S R R College, Karimnagar 505 002, India \\ *Department of Physics, Kakatiya University, Warangal 506 009, India
}

MS received 11 July 1981 ; revised 9 September 1981

\begin{abstract}
A simple and inexpensive technique for obtaining the interference microtopographs of crystal surfaces is reported. The method consists of forming a low angle air wedge by placing a thin glass sheet (cover slide) on the surface of the sample. Interferograms are taken under reflected sodium light.
\end{abstract}

Keywords. Interference microtopograph ; growth micromorphology ; surface steps.

\section{Introduction}

Interference; microtopography is a very useful technique in studying the growth micromorphology of crystal surfaces and the surface structure of deformed materials ( slip steps, kink walls etc.). Tolansky (1948. 1968) has established the advantages of interferometric techniques in microtopographic studies. The vertical resolution attainable is high in the case of multiple beam interference methods compared to the double beam interference techniques (Blakely 1973). The interference microscopes are quite expensive and the technique described below for obtaining interferograms is extremely simple and inexpensive. Our method can effectively be used in laboratories where interference microscopic facilities are not available.

\section{Technique}

In multiple beam method as employed here it is necessary to form a thin, low angle air wedge. This is achieved by placing a good quality cover slide (thickness : $0.2 \mathrm{~mm}$ ) on the top surface of the sample. The thin air wedge is obtained in case of samples having a flat surface by elevating one edge of the glass cover slide by using a piece of thin wire. The wedge angle $\alpha$ can be calculated using the expression (Born and Wolf 1970). 


$$
\alpha=\frac{\lambda}{2 \beta},
$$

where $\beta$ is fringe width and $\lambda$ is wave length. The step heights $(\Delta h)$ on crystal surfaces can be calculated, using the equation

$$
\Delta h=\frac{\lambda}{2} \Delta m,
$$

where $\Delta m$ is the ratio of the fringe. shift and the fringe width.

\section{Observations}

Microscopic observations were made under reflected light employing a "meopta" microscope. The normal bulb used as light source is replaced by a sodium vapour lamp. The fringe width and the fringe shift are measured from the negative film using a low power microscope in conjunction with a micrometer eyepiece or using a sensitive comparator. As the fringe width is inversely proportional to the wedge angle care must be exercised in placing the cover slide on the sample surface, so that a suitable fringe spacing results. The interferograms presented here are comparable in quality to those obtained by using an interference microscope (Budke 1969). The quality of the interferograms can be enhanced by coating the surface of the sample with silver, however the interferograms presented in this article were taken without providing any such coating on the sample surface.

In order to illustrate the effectiveness of this technique interferograms showing the typical growth features of $n$-alkane crystals grown from solutions is presented. Figure 1a shows a growth spiral photographed under transmitted light and Figure $1 \mathrm{~b}$ is its interferogram. The spiral step heights are found to be around $0.17 \mu \mathrm{m}$. Figure 2, shows a triangular growth island on a rhombic platelet. Detailed results on growth micromorphology of $n$-alkane crystals will be published later.

\section{Acknowledgements}

The authors thank Prof. D B Sirdeshmukh, Head, Department of Physics, Kakatiya University, Warangal for helpful discussions and encouragement.

\section{References}

Blakely J M 1973 Introduction to the properties of crystal surfaces (International series on material science and technology) (New York: Pergamon) 12123

Born M and Wolf E 1970 Principles of optics (New York : Pergamon) 356

Budke J 1969 J. Appl. Phys. 40641

Tolansky S 1948 Multiple beam interferometry of surfaces and films (London: Clarendon)

Tolansky S 1968 Microtopography of surfaces using interferometry (London : Edward Arnold) 


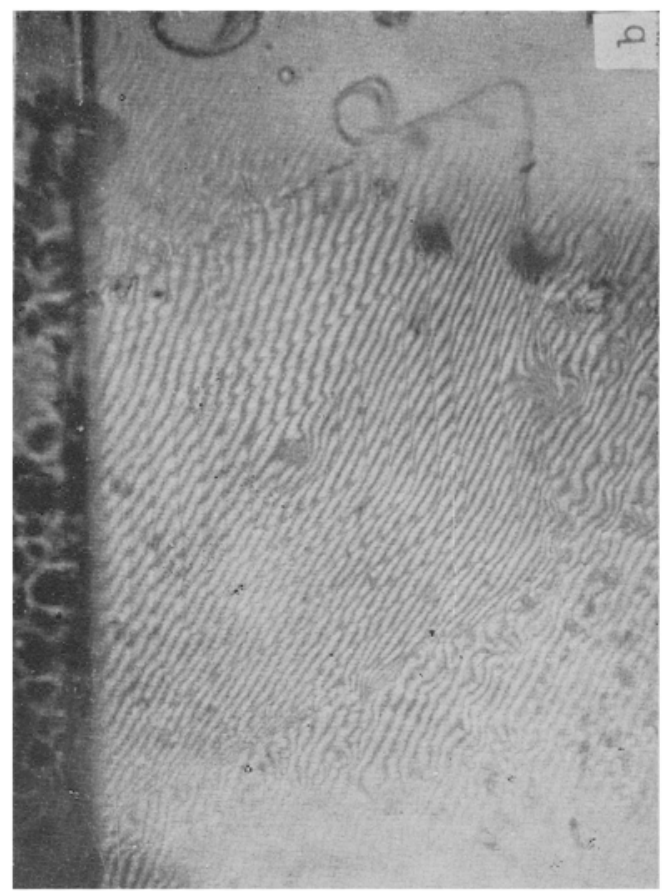

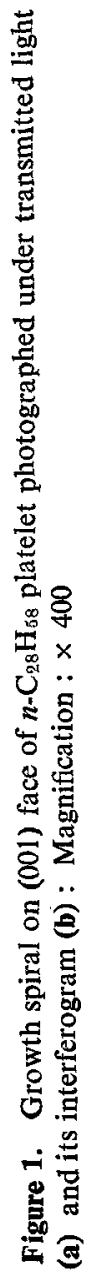

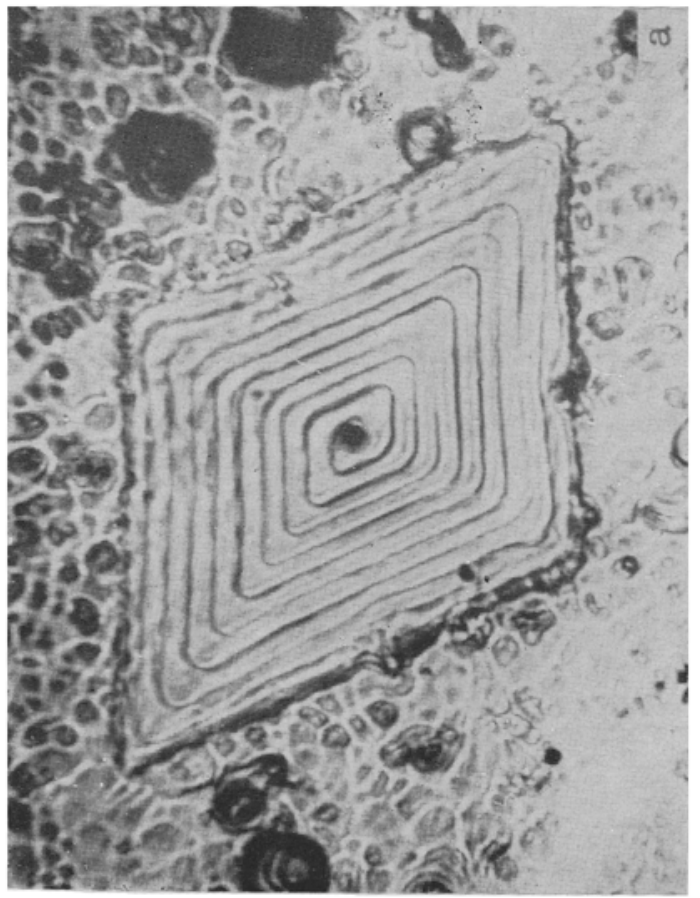




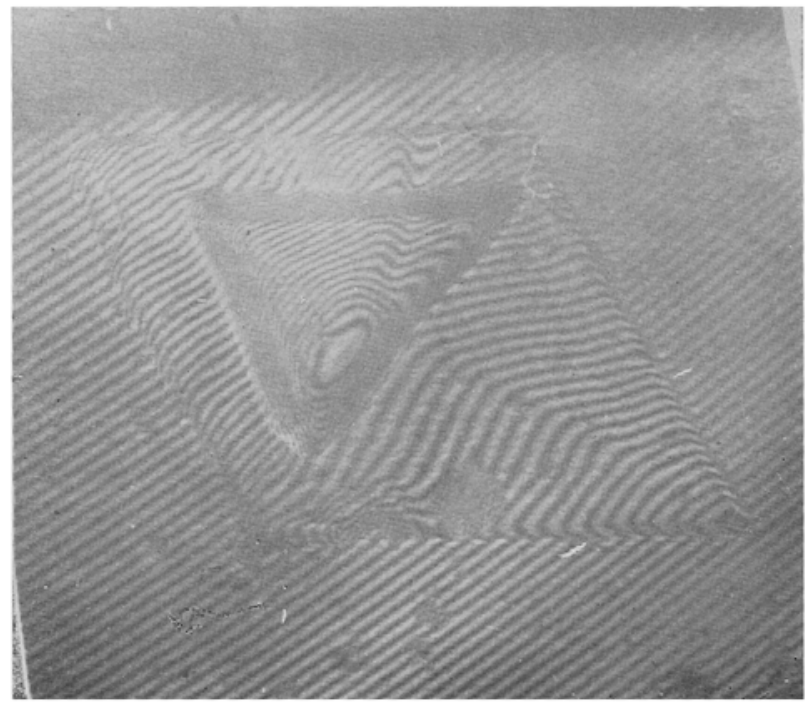

Figure 2. Interferogram of a triangular island on (001) face of a rhombic platelet of $n-\mathrm{C}_{28} \mathrm{H}_{58}$. Magnification : $\times 400$. 